\title{
Health system reform: a Latin American country's perspective
}

\begin{abstract}
Global health services are provided in multiple forms, whether the government pays expenses through taxes, small contributions and insurers, or a combination of these, among other forms. In Mexico and Latin America there are situations of inequality and poor health indicators, which forces us to analyze the health system. It has planted 2 roads, correct the errors of the same system or a total reform that includes the unification of the fragmented system we have. Whatever path is taken, this will result in experiences from which everyone can learn our mistakes and successes that can be used to find the ideal health system.
\end{abstract}

Keywords: health reform, Latin America, Mexico, health system, fiscal reform, maternal mortality, human resources, health indicators, population, workers
Volume 2 Issue 4 - 2018

\author{
Alan Johan chavolla Canal,' Gloria Fernanda \\ Martinez Bernal ${ }^{2}$ \\ 'General Surgeon and Urologist in Urology Service, University \\ of Guadalajara, Mexico \\ ${ }^{2}$ Anesthesiologist in Anaesthesiology Service, Mexican Social \\ Security Institute IMSS, Mexico
}

Correspondence: Alan Johan Chavolla-Canal, General Surgeon and urologist in Urology Service, University of Guadalajara, Mexico,Tel 33I4055654, Email radiohead_56@hotmail.com

Received: June 08, 2018 | Published: July II, 2018

\section{Introduction}

Mexico's health system is a public system comprised of various insurance and service providers with very little contact amongst each other and approximately $50 \%$ of Mexico's population belong to this system. There are, besides, other health state services to which the rest of the population belongs. ${ }^{1,2}$ It is also composed by a great unregulated private sector (approximately one third of hospital beds in Mexico belong to the private sector). ${ }^{1}$ Mexico's life expectancy has increased; nonetheless it is still beneath all health indicators for countries belonging to the OECD (Organization for Economic Co-operation and Development), including maternal mortality. ${ }^{1}$ The health budget is as low as $2.8 \%$ of the gross domestic product, which is questionable when comparing Mexico to other countries (even in Latin America). Among the many problems and challenges faced are a generally deficient system, decentralized politics, lack of administrative capacity, lack of rewards for productivity and quality services as well as a highly deficient pharmaceutical coverage. ${ }^{1,2}$ The challenges that await for a new health reform are the transition with the pension system, health insurance coverage (which requires more services), better quality and efficiency, among others..$^{3-5}$ A new fiscal reform is required for this health reform, to accompany changes in the pension system, acceptance of a unique health service provider, adequate financing of epidemiologic vigilance, preventive medicine, promotion of quality and productivity, training of personnel, and transparency of administrative processes. ${ }^{1}$

\section{Health system in Mexico}

Since the ending of the Mexican Revolution in 1920, Mexico's health policy has been to control infectious diseases, to further health services where there are none, and planned parenthood. For these purposes, several institutions were created, starting with IMSS (Mexican Institute for social security) and Health Secretary (Secretaria de Salud) founded in 1943, ISSSTE (Institute of security and social service of state workers)in 1960, and afterwards state services appeared. ${ }^{1,2}$ But since then priorities have changed, our current situation is dire in spite of having improved health policies, we're still the second poorest country in the OECD with the most unequal distribution of wealth, with a high marginalization index in 6 states, and $9.5 \%$ of the country with analphabetism. Infectious diseases have decreased but chronic diseases have been on the rise (Mexico having the highest prevalence of diabetics in the OECD, almost $16 \%$ of its population by 2017)., Mexico still has a large gap of uninsured population. Of the total population, $40 \%$ of Mexicans belong to IMSS, $9 \%$ to ISSSTE, and $2 \%$ to state services, leaving $49 \%$ of the population with no insurance, to be covered by services like IMSS oportunidades and Secretaria de Salud. ${ }^{2}$ Besides, analyzing the health budget a total of $33 \%$ is destined for hospitalization, $30.8 \%$ for consultation, and $21.6 \%$ for pharmaceutical drugs, leaving a small margin for personnel. Compared to other countries we have more money destined for health but worse health indicators. ${ }^{1-5}$ Therefore, medicine in Mexico is expensive and inefficient.

\section{Conclusion}

The health system reform according to WHO guidelines requires a legal framework to sustain it to be able to insure the citizenship access to health services and insurance coverage. The main objectives of the new health reform should be to broaden the services offered, creation of a unique package to guarantee equal coverage, expand primary care services, pension system reform, increase efficiency through incentives, creation of new management models, increase social involvement and health awareness, promote quality human resources, and guarantee quality technology. The principal challenges to achieve this health reform are: a complex health system, public sector underfunded and inefficient, unequal distribution of health services, financing and a lack of transparency. The health system reform has been a long way coming in Mexico as a plan to tackle the deficiencies presented in the health system, but also to expand health services and to improve health issues that take priority in our population. In other Latin American countries where they applied the health reform according to the WHO guidelines, goals haven't been achieved yet, but it's important to remember that the process is slow and that it is vital to evaluate results in order to adjust accordingly. 


\section{Acknowledgments}

None.

\section{Conflict of interest}

The author declares there is no conflict of interest.

\section{References}

1. OECD. Reviews of Health Care Systems: Mexico. 2016.

2. Gobierno de la Republica. Plan Nacional de Desarrollo, Programa Sectorial de Salud. 2013.
3. Infante A, de la Mata I, Lopez-Acuna. Reforma de los sistemas de salud en América Latina y el Caribe: situación y tendencias. Pan Am J Public Health. 2000;8(2):13-20.

4. CEPAL. Los objetivos de desarrollo del Milenio y los desafíos para América Latina y el Caribe para avanzar en mayor bienestar, mejor capital humano y más igualdad de oportunidades. 2007. p. 1-97.

5. Arriagada I, Aranda V, Miranda F. Políticas y programas de salud en América Latina. Problemas y propuestas. 2005. p. 1-67. 